\title{
Innate differences and colostrum-induced alterations of jejunal mucosal proteins in piglets with intra-uterine growth restriction
}

\author{
Xiaoqiu Wang ${ }^{1} \dagger$, Yuhua Zhu ${ }^{1,2}$, Cuiping Feng ${ }^{3}$, Gang $\operatorname{Lin}^{1}$, Guoyao Wu ${ }^{1,4}$, Defa Li $^{1}$ and Junjun Wang ${ }^{1,2 *}$ \\ ${ }^{1}$ State Key Laboratory of Animal Nutrition, China Agricultural University, Beijing 100193, People's Republic of China \\ ${ }^{2}$ Beijing Advanced Innovation Center for Food Nutrition and Human Health, China Agricultural University, Beijing 100193, \\ People's Republic of China \\ ${ }^{3}$ Department of Obstetrics and Gynecology, China-Japan Friendship Hospital, Beijing 100029, People's Republic of China \\ ${ }^{4}$ Department of Animal Science, Texas AEM University, College Station, TX 77843, USA
}

(Submitted 4 October 2017 - Final revision received 17 January 2018 - Accepted 18 Jamuary 2018)

\section{Abstract}

Mammalian neonates undergo rapid transitions from a sterile uterine environment with a continuous intravenous supply of nutrients to a microbe-rich environment with intermittent ingesting of colostrum/milk via the gut. Currently, little is known about the colostrum-induced alterations of intestinal mucosal proteins in piglets with intra-uterine growth restriction (IUGR). In this study, we sought to investigate the innate differences and effects of colostrum on alterations in small-intestinal proteomes of IUGR piglets. Two IUGR (approximately 0.9 kg) and two normal-birth weight (NBW; approximately $1.3 \mathrm{~kg}$ ) piglets were obtained from each of six sows at birth. One half ( $n$ 12; 6 IUGR $v .6$ NBW) of the selected newborn piglets were killed to obtain jejunum samples, and the other half ( $n 12 ; 6$ IUGR $v$. 6 NBW) of the newborn piglets were allowed to suckle colostrum from their own mothers for $24 \mathrm{~h}$ before jejunum sample collection. On the basis of proteomic analysis, we identified thirty-one differentially expressed proteins in the jejunal mucosa between IUGR and normal neonates before or after colostrum consumption. The intestinal proteins altered by colostrum feeding play important roles in the following: (1) increasing intestinal integrity, transport of nutrients, energy metabolism, protein synthesis, immune response and, therefore, cell proliferation; and (2) decreasing oxidative stress, and therefore cell apoptosis, in IUGR neonates. However, colostrum only partially ameliorated the inferior status of the jejunal mucosa in IUGR neonates. These findings provide the first evidence in intestinal protein alterations of IUGR neonates in response to colostrum ingestion, and thus render new insights into the mechanisms responsible for impaired growth in IUGR neonates and into new nutritional intervention strategies

\section{Keywords: Jejunum: Colostrum: Porcine neonates: Intra-uterine growth restriction: Proteomics}

Intra-uterine growth restriction (IUGR), defined as impaired growth and development of the mammalian embryo/fetus or its organs during pregnancy, is a leading cause of neonatal morbidity and mortality in humans, as well as livestock species ${ }^{(1)}$. Inadequate delivery of nutrients during pregnancy directly results in IUGR, which can be measured as birth weight below the 10th percentile when adjusted for gestational age and sex ${ }^{(2,3)}$. Moreover, other factors (uterine capacity, heat stress, disease and toxins) that interfere with the delivery of nutrients during pregnancy are considered as the indirect causes of IUGR. Despite advanced prenatal care for both mothers and fetuses, approximately $5-10 \%$ of human infants worldwide suffer from $\mathrm{IUGR}^{(4)}$.
Of domestic livestock species, the pig exhibits the most IUGR occurrences, and is an established animal model for studies of IUGR during prenatal and postnatal lives - that is, fetal programming and nutrient intervention ${ }^{(5-8)}$

Colostrum, which is a nutrient-rich fluid produced by female mammals immediately after giving birth, is the first source and true personalised diet of neonates. Not only can it provide nutrients, but it also mediates control of biological functions via protective Ig, as well as antimicrobial and anti-inflammatory factors, thereby improving early gastrointestinal development and increasing the survival rate of mammalian neonates ${ }^{(9-11)}$. Particularly in pigs, there is very limited transport of maternal Ig

Abbreviations: ACTB, $\beta$-actin; ALB, albumin; ANXA4, annexin A4; ANXA5, annexin A5; BW, body weight; CALM, calmodulin; CALR, calreticulin; CAT, catalase; CPS1, carbamoyl-phosphate synthetase 1; D0, day 0; D1, day 1; EEF2, eukaryotic translation elongation factor 2; EIF5A, eukaryotic translation initiation factor 5A-1; EIF6, eukaryotic translation initiation factor 6; FBP1, fructose 1,6-bisphosphatase; GRP78, glucose-regulated protein; HSPA1B, heat shock 70 kDa protein 1B; IUGR, intra-uterine growth restriction; LMNA, lamin A/C; MFGE8, milk fat globule-EGF factor 8 protein; NBW, normal-birth weight; PRDX1, peroxiredoxin 1; RPSA, laminin receptor 1; SDHA, succinate dehydrogenase complex subunit A; STRAP, serine/threonine kinase receptor-associated protein; TF, transferrin; VCL, vinculin.

* Corresponding author: J. Wang, email jkywjj@hotmail.com

$\dagger$ Present address: Reproductive and Developmental Biology Laboratory, National Institute of Environmental Health Sciences, National Institute of Health, Research Triangle Park, NC 27709, USA. 
across the placenta, and therefore colostrum is the only source of Ig for porcine neonates ${ }^{(12,13)}$. Gastrointestinal health is critical for both human medicine and animal production because of its irreplaceable role in nutrient digestion, absorption and metabolism, as well as the defensive barrier against exogenous pathogens ${ }^{(14-16)}$. The small intestine is divided into three distinct regions: duodenum, jejunum and ileum; among these regions, the jejunum serves as the major portion for absorption of carbohydrates, amino acids and fatty acids into the circulation. It consists of mucosa (epithelium, lamina propria and the muscularis mucosae), submucosa, muscularis and serosa, from the innermost to outermost layers. Results of our previous studies revealed that IUGR (1) affects the expression of proteins associated with developmental reprogramming of the fetal gut during gestation, and (2) continuously impairs gut development during the nursing period $^{(6-8)}$. However, innate differences in intestinal mucosal proteins at birth and, more importantly, colostrum-feedinginduced changes in intestinal proteome on alterations of intestinal proteomes in IUGR neonates are still unknown.

We hypothesised that colostrum consumption plays an important role in regulating the expression of intestinal proteomes in IUGR piglets. This hypothesis was tested by quantifying changes in jejunal mucosal proteins between normal and IUGR neonates with or without colostrum intake.

\section{Methods}

\section{The piglet model and tissue collection}

During the period of gestation, primiparous gilts (Large White sires $\times$ Landrace dams; $n 6$ litters) were fed $2 \mathrm{~kg} / \mathrm{d}$ (from days 0 to 85 of gestation) and then $2.5 \mathrm{~kg} / \mathrm{d}$ (from day 85 to term) of a maize and soyabean-meal-based diet and had free access to drinking water, as we described previously ${ }^{(6,7,17-19)}$. Six litters of porcine neonates (Large White $\times$ Landrace $\times$ Pietran) were delivered from sows at term (day 114 of gestation). On day 0 (D0, without sucking colostrum), body weights (BW) of all neonatal piglets were recorded immediately upon birth. On the basis of the BW, two IUGR male piglets (approximately $0.9 \mathrm{~kg}$ ) and two normal-birth weight (NBW; approximately $1.3 \mathrm{~kg}$ ) male piglets were obtained from each of the six litters. One half ( $n$ 12; six IUGR $v$. six NBW) of the selected piglets were killed by jugular puncture after anaesthesia, as we described preciously $^{(6)}$. The other half ( $n 12$; six IUGR $v$. six NBW) of the selected piglets were positioned on the second teat pairs (known as anterior mammary glands) ${ }^{(20)}$, suckling colostrum from their own mothers for $24 \mathrm{~h}$. The farrowing pen was partially covered with a heat lamp to maintain the optimal temperature $\left(32-34^{\circ} \mathrm{C}\right)$ for piglets. On day 1 (D1), the remaining half of the selected neonatal piglets were weighed again and then killed by jugular puncture after anaesthesia. Tissues from all selected porcine IUGR and NBW neonates were collected. The small intestine of neonatal pigs was defined as the portion of the digestive tract between the pylorus and the ileocecal valve, with the first $10-\mathrm{cm}$ segment being the duodenum, and the subsequent 40 and $60 \%$ of the small intestine length below the duodenum being the jejunum and the ileum, respectively ${ }^{(6)}$. The luminal content of the jejunum was rapidly removed with saline ${ }^{(8,21)}$. After measuring the length and weight of the whole jejunum, the mucosa from the jejunum was obtained by careful scraping of the mucosal layer using a glass microscope slide as described previously ${ }^{(8,15)}$, and then it was snap-frozen in liquid $\mathrm{N}_{2}$ and stored at $-80^{\circ} \mathrm{C}$ for proteomic and Western blot analyses. The animal use protocol was reviewed and approved by the China Agricultural University Animal Care and Use Committee.

\section{Protein extraction of the jejunal mucosa}

Proteins were extracted from the jejunal mucosa as we described $^{(7,8,15)}$. In brief, frozen jejunal mucosal samples (approximately $50 \mathrm{mg}$ ) were homogenised in a lysis buffer (7 m solid urea, $2 \mathrm{~m}$ thiourea, 4\% CHAPS (3-[(3-cholamidopropyl)dimethylammonio]-1-propanesulfonate) and $15 \mathrm{~mm}$ TRIS, pH 8.5) containing $1 \%$ protease inhibitors (100×; GE Healthcare). Tissues were ruptured at $0^{\circ} \mathrm{C}$ using an Ultrasonicater Model VCX 500 (Sonics \& Materials) at $20 \%$ power output for $10 \mathrm{~min}$ with 2-s on and 8-s off cycles. After the addition of $1 \%(\mathrm{v} / \mathrm{v})$ nuclease mix (GE Healthcare), the lysed cell suspension was kept at $25^{\circ} \mathrm{C}$ for $1 \mathrm{~h}$ to solubilise proteins ${ }^{(17,22)}$, followed by re-sonication as described above to thoroughly break up cell membranes. The homogenate was subsequently centrifuged for $10 \mathrm{~min}$ at $13000 \mathrm{~g}$ at $4^{\circ} \mathrm{C}$. The supernatant fluid was collected, and its protein concentration was determined using a PlusOne 2-D Quant Kit (GE Healthcare). Protein extracts were stored in aliquots (1 mg of protein) at $-80^{\circ} \mathrm{C}$.

\section{Difference gel electrophoresis and MS analysis}

Proteins in each group were labelled with Cy2, Cy3 or Cy5 (Amersham Biosciences) according to the manufacturer's protocol. To avoid any dye-specific labelling artefacts, samples in each group were labelled with either Cy3 or Cy5 (400 pmol dye $/ 50 \mu$ g protein). The internal reference, which is a mixture of $25 \mu \mathrm{g}$ of protein from each of twelve samples (consisting of $300 \mu \mathrm{g}$ of protein), was labelled with Cy2. A differentially labelled sample for each gel consists of two portions: 1) a combination of two samples $(50 \mu \mathrm{g}$ protein/sample, Cy5- or Cy3-labelled) from four different groups (IUGR-D0, NBW-D1, IUGR-D0 and NBW-D1) in the study, and (2) an internal reference (see online Supplementary Table S1). A total of six gels were run for the two-dimensional fluorescence difference gel electrophoresis (DIGE) through isoelectric focusing and standard vertical SDS-PAGE (12.5\%), both in the dark, as previously described ${ }^{(23)}$. The gels were imaged using Typhoon 9400 laser scanner (GE Healthcare), as described by Lilley ${ }^{(24)}$. Images were analysed using the DeCyder version 6.5 software (GE Healthcare $)^{(25)}$. Differentially expressed protein spots $(P<0.05)$ with a deviation of over 1.2 -fold were selected as protein spots of interest (POI).

\section{In-gel digestion}

The DIGE gels were aligned with Coomassie-stained 2D gels and the POI were obtained manually for in-gel digestion, as we previously described $^{(6-8,15)}$. In brief, the POI were destained with $100 \mu \mathrm{l}$ of $50 \%(\mathrm{v} / \mathrm{v})$ acetonitrile (ACN) in $25 \mathrm{mmol} / \mathrm{l}$ ammonium bicarbonate for $1 \mathrm{~h}$. After the protein samples were completely dried by vacuum centrifugation (Eppendorf 
Concentrator 5301; Sigma) for $30 \mathrm{~min}$, they were digested with $2 \mu \mathrm{l}$ of trypsin $(12.5 \mathrm{ng} / \mu \mathrm{l}$; Ameresco Inc.) in $25 \mathrm{mmol} / \mathrm{l} \mathrm{ammo-}$ nium bicarbonate at $4{ }^{\circ} \mathrm{C}$ for $1 \mathrm{~h}$, and then incubated at $37^{\circ} \mathrm{C}$ for $12 \mathrm{~h}$. The resulting peptides were sequentially extracted (three times at $37^{\circ} \mathrm{C}$ ) with $8 \mu$ l each of $5 \%$ trifluoroacetic acid (TFA) for $1 \mathrm{~h}, 2.5 \%$ TFA in $50 \% \mathrm{ACN}$ for $1 \mathrm{~h}$ and $100 \% \mathrm{ACN}$ for $1 \mathrm{~h}$. Extracted protein samples were dried by vacuum centrifugation.

\section{Protein identification by MS and database search}

Peptides from in-gel digested proteins were mixed with a matrix solution ( $\alpha$-cyano-4-hydroxycinnamic acid in $0 \cdot 1 \%$ TFA and $50 \% \mathrm{ACN}$ ). Matrix-assisted laser desorption ionisation-time of flight MS (MALDI-TOF MS) analysis for protein identification was carried out (Bruker Reflex Daltonik). The parameters used for the MALDI-TOF MS analysis were $20 \mathrm{kV}$ accelerating voltage and $23 \mathrm{kV}$ reflecting voltage. Protein identification was achieved through Peptide Mass Fingerprint searches using GPS Explorer Workstation (Applied Biosystems) with the in-house searching engine Mascot and the searching taxonomy of Mammalia against the NCBInr database. Search parameters included the following: (1) trypsin, as the enzyme of protein digestion; (2) monoisotopic, as mass value; (3) unrestricted, as peptide mass; (4) $\pm 0 \cdot 3 \mathrm{Da}$, as peptide mass tolerance; (5) oxidation (M) and carbamidomethyl (C), as variable modifications; and (6) 1, as maximum missed cleavages. In this procedure, a protein match with a score $>71$ was considered significant $(P<0 \cdot 05)$.

\section{Western blot analyses}

Extracted proteins $(30 \mu \mathrm{g} / \mathrm{sample})$ were denatured, separated using SDS-PAGE ( 4 to $12 \%$ gradient gel at $150 \mathrm{~V}$ for $2 \cdot 5-3 \mathrm{~h}$ ) and transferred to a nitrocellulose membrane overnight (approximately $16 \mathrm{~h}$ ) at $20 \mathrm{~V}$ using the Bio-Rad Transblot (Bio-Rad). Membranes were blocked in $5 \%$ fat-free milk in $20 \mathrm{mmol} / 1$ TRIS, $150 \mathrm{mmol} / 1 \mathrm{NaCl}, \mathrm{pH} 7 \cdot 5$, and $0.1 \%$ Tween-20 (TBST) for $3 \mathrm{~h}$ and then incubated with a primary antibody (i.e. anti- $\beta$-actin (ACTB) (1:2000; \#4970), anti-transferrin (TF) (1:2000; ab82411), anti-glucose-regulated protein (GRP78) (1:1000; \#3183) or antialbumin (ALB) $(1: 1000 ; \# 4929))$ at $4^{\circ} \mathrm{C}$ overnight with gentle rocking. After washing three times with TBST, the membranes were incubated for $2 \mathrm{~h}$ with a secondary antibody (horseradishperoxidase-linked anti-rabbit IgG) at 1:10000 dilution. The membranes were then washed with TBST, followed by development using enhanced chemiluminescence detection (SuperSignal West Pico) according to the manufacturer's instructions. Western blots were quantified by measuring the intensity of light emitted from correctly sized bands under ultraviolet light using a ChemiDoc EQ system and Quantity One software (Bio-Rad). All the antibodies were purchased from Cell Signaling Technology, except for TF (ab82411; Sigma-Aldrich). Multiple exposures of each Western blot were performed to ensure linearity of chemiluminescence signals.

\section{Statistical analysis}

The minimum sample size of four animals per group ( $n 6$ in the study) was calculated using the glutathione $S$-transferase activity in the jejunum of piglets as the primary outcome ${ }^{(15)}$, in which the effect size is 2.55 with adjustment of the statistical power to 0.8 and the $\alpha$ error to 0.05 . Litter variation $(P>0.05)$ was tested using linear regression model (mixed-effect). Normality of original data and homogeneity of variance were tested using the Shapiro-Wilk test and the Brown-Forsythe test, respectively, in SAS 8.1 (SAS Institute). A logarithmic transformation was applied to the fold change of protein abundance in order to generate Fig. 3. Ingenuity Pathway Analysis (IPA) software was further applied for bioinformatic analyses. The same amount of total protein loaded from each biological sample was used as internal control for Western blot analysis. Protein expression of NBW sample at D0 was used as the denominator, by which the protein expressions of all samples were normalised and compared. Data were analysed by least-squares one-way ANOVA, as well as the Fisher's least significant difference as post boc analysis, with each animal identified as an experimental unit. All analyses were performed using SAS. Data are expressed as means with their standard errors, and values of $P<0.05$ were considered significant.

\section{Results}

Body weights, jejunal lengths and weights of porcine neonates

BW of IUGR and NBW porcine neonates at birth (D0) were 890 and $1330 \mathrm{~g}$, respectively $(P<0 \cdot 05)$. After $24 \mathrm{~h}$ of colostrum ingestion (D1), BW of IUGR and NBW porcine neonate were 960 and $1520 \mathrm{~g}$, respectively $(P<0 \cdot 05)$. Between D0 and D1 after birth, BW of NBW neonates increased $14.2 \%(P<0.01)$ in response to colostrum ingestion, whereas no difference was observed in IUGR neonates (Fig. 1(A)). Moreover, IUGR neonates continued to have a lower $(P<0.01)$ BW than NBW neonates at different time points (Fig. 1(A)).

The jejunal length and weights of IUGR and NBW porcine neonates between D0 and D1 after birth are presented in Fig. 1(B-E). The absolute jejunal length of IUGR neonates (Fig. 1(B)) was shorter $(P<0 \cdot 01)$ than that of NBW neonates, at each time point (D0 and D1), and the absolute jejunal weight of IUGR neonates (Fig. 1(D)) was also lower $(P<0.01)$ than that of NBW neonates at both D0 and D1. When compared between D0 and D1 (colostrum effect), no differences were observed in the absolute jejunal length of either NBW or IUGR groups (Fig. 1(B)). However, the absolute jejunal weight of NBW neonates increased $61.0 \%$ between D0 and D1 in response to colostrum ingestion, whereas that of IUGR piglets remained unchanged (Fig. 1(D)) between D0 and D1. Compared with NBW neonates, the relative jejunal length (jejunal length/BW; Fig. 1(C)) in IUGR neonates remained higher $(P<0.05)$ on both D0 and D1, whereas the relative jejunal weight (jejunal weight/BW; Fig. 1(E)) in IUGR neonates was not different on D0 and was lower $(P<0.05)$ on $\mathrm{D} 1$.

\section{Temporal analysis of proteins}

A total of thirty-one protein spots were differentially expressed in the jejunal mucosa between IUGR and NBW fetuses at D0 and D1 of age. Biochemical information regarding these protein spots is summarised in Table 1, whereas their appearance on 
(A)

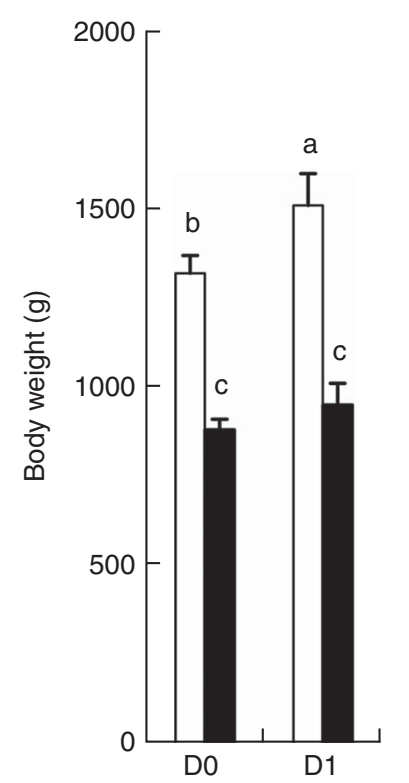

(B) 400

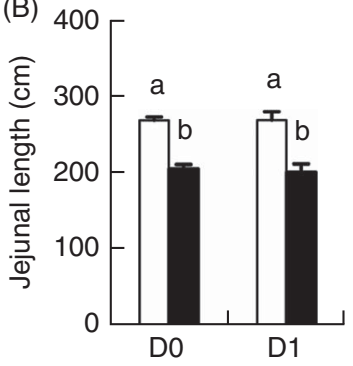

(C)

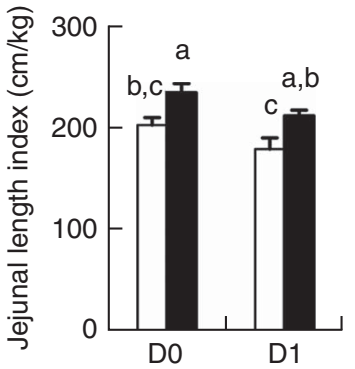

(D)

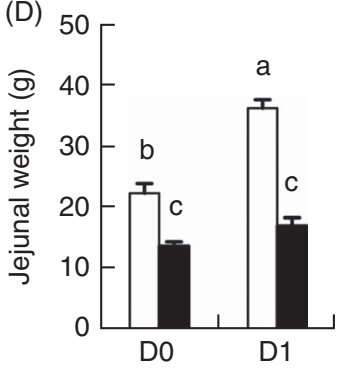

(E)

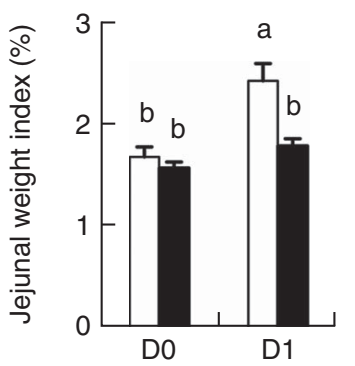

Fig. 1. Body weight $(A)$, absolute $(B)$ and relative $(C)$ length of the jejunum, as well as absolute (D) and relative (E) weights of the jejunum of intra-uterine growth restriction (IUGR, $\square$ ) and normal-birth weight (NBW, $\square$ ) piglets at days 0 (D0) 1 (D1). Jejunal length index=jejunal length/body weight. Jejunal weight index =jejunal weight/body weight $\times 100 \%$. Values are means ( $n 6$ for each group at D0 and D1), with their standard errors represented by vertical bars. ${ }^{\text {a,b,c }}$ Mean values with unlike letters were significantly different $(P<0.05)$ among groups.

the gel images is labelled in Fig. 2 and their log-transformed expression level is quantified in Fig. 3. On the basis of their biological functions, these proteins are classified into several groups: (1) transport of nutrients; (2) cell structure and motility; (3) glucose and energy metabolism; (4) immune response; (5) protein metabolism; (6) redox homoeostasis and stress response; and (7) cell proliferation and apoptosis.

\section{Transport of nutrients}

Five spots of proteins were related to transport of nutrients (Fig. 3(a)). They are ALB (Spot 1127, 1851), $\alpha$-fetoprotein (AFP; Spot 807), TF (Spot 910) and apoA-IV (APOA4; Spot 2125). At birth (D0), APOA4 abundance was lower $(P<0.05)$ in the jejunal mucosa of IUGR neonates compared with NBW neonates; however, no differences $(P>0.05)$ in abundances of ALB, AFP and TF were detected in the jejunal mucosa between IUGR and NBW neonates. After $24 \mathrm{~h}$ of colostrum ingestion (D1), both IUGR and NBW neonates displayed increases $(P<0.05)$ in ALB, TF and APOA4 in the jejunal mucosa with a lesser extent in the IUGR group, as evidenced by their lower $(P<0.05)$ abundance in IUGR than NBW jejunal mucosa at D1. Interestingly, AFP was decreased $(P<0.05)$ in the jejunal mucosa of NBW neonates, but remain unchanged $(P>0.05)$ in IUGR between D0 (colostrum negative) and D1 (colostrum positive).

\section{Cell structure and motility}

Four spots of proteins were related to cell structure and motility (Fig. 3(b)). They are lamin A/C (LMNA; Spot 1071), laminin receptor 1 (RPSA; Spot 1734), ACTB (Spot 2483) and vinculin (VCL; Spot 434). At D0, the abundances of LMNA, RPSA, ACTB and VCL were lower $(P<0.05)$ in the jejunal mucosa of IUGR neonates as compared with NBW neonates. After colostrum intake, both IUGR and NBW neonates exhibited increases $(P<0.05)$ in LMNA in the jejunal mucosa. However, LMNA was still lower $(P<0.05)$ in the IUGR jejunal mucosa than that of NBW at D1. In addition, RPSA, ACTB and VCL remained unchanged $(P>0.05)$ in the jejunal mucosa of NBW neonates, but increased $(P<0.05)$ in the IUGR by colostrum ingestion at D1 as compared with the respective group at D0.

\section{Glucose and energy metabolism}

Two spots of proteins were related to glucose and energy and metabolism (Fig. 3(c)), which are mitochondrial succinate dehydrogenase complex subunit A (SDHA; Spot 1066) and fructose-1,6-bisphosphatase (FBP1; Spot 2215). At D0, the abundance of FBP1 was higher $(P<0.05)$ in IUGR jejunal mucosa compared with the NBW group; however, no difference in the abundance of SDHA was detected in the jejunal mucosa between IUGR and NBW neonates. After colostrum intake, both IUGR and NBW neonates exhibited increases $(P<0.05)$ in SDHA with a lesser extent in the IUGR jejunal mucosa, as evidenced by its lower $(P<0.05)$ abundance in IUGR than NBW at D1. Interestingly, FBP1 was decreased $(P<0.05)$ in the jejunal mucosa of NBW neonates, but remained unchanged $(P>0 \cdot 05)$ in IUGR between D0 and D1.

\section{Immune response}

Four spots of proteins were associated with immune response (Fig. 3(d)). They are Ig $\gamma$-3 chain C region (IGHG3; Spot 539, 1493), Ig $\gamma-4$ chain $\mathrm{C}$ region (IGHG4; Spot 1435) and Ig $\gamma$-2B chain $\mathrm{C}$ region (IGHG2B; Spot 2019). At D0, the abundances of IGHG3 and IGHG4 were lower $(P<0.05)$ in the jejunal mucosa of IUGR 


\section{Nes British Journal of Nutrition}

Table 1. Biochemical information about proteins differentially expressed in the jejunual mucosa of intra-uterine growth restriction and normal-birth weight neonates (days 0 (D0) and 1 (D1))

\begin{tabular}{|c|c|c|c|c|c|c|c|c|}
\hline Spot no. ${ }^{*}$ & Protein name & Abbreviation & $\begin{array}{l}\text { Accession } \\
\text { no. }\end{array}$ & $\begin{array}{l}\text { Protein } \\
\text { score }\end{array}$ & $\begin{array}{l}\text { Theoretical } \\
\text { MW (Da) }\end{array}$ & $\begin{array}{l}\text { Theoretical } \\
\mathrm{pl}\end{array}$ & Subcellular location & Functions \\
\hline \multicolumn{9}{|c|}{ Transport of nutrients } \\
\hline 1127 & Albumin (Sus scrofa) & ALB & gil833798 & 170 & 69366 & 5.92 & Secreted; extracellular region & Transport \\
\hline 1851 & Albumin (Sus scrofa) & ALB & gil124257959 & 106 & 69554 & 5.92 & Secreted; extracellular region & Transport \\
\hline 807 & $a$-Fetoprotein (Sus scrofa) & AFP & gil47523700 & 224 & 68580 & $5 \cdot 47$ & Extracellular space & Transport \\
\hline 910 & Transferrin (Sus scrofa) & & gill833800 & 85 & 76901 & 6.73 & Secreted; extracellular region & Iron transport \\
\hline 2125 & Apolipoprotein A-IV (Sus scrofa) & APOA4 & gil47523830 & 227 & 43268 & 5.69 & Secreted; HDL particle & Lipid transport \\
\hline \multicolumn{9}{|c|}{ Cell structure and motility } \\
\hline 1071 & Lamin A/C (Sus scrofa) & LMNA & gil162139823 & 103 & 74174 & 6.73 & Intermediate filament; nucleus & Nuclear envelope organisation \\
\hline 1734 & Laminin receptor 1 (Sus scrofa) & RPSA & gil80971504 & 107 & 32907 & 4.80 & Cytoplasm; nucleus & Cell adhesion; translational elongation \\
\hline 2483 & $\beta$-Actin (Bos taurus) & ACTB & gil162606 & 80 & 17421 & 4.95 & Cytoplasm & Cytoskeleton \\
\hline 434 & Vinculin (Sus scrofa) & VCL & gil47522618 & 172 & 116803 & 5.89 & Cytoskeleton & $\begin{array}{l}\text { Cell adhesion; regulation of cell } \\
\text { migration }\end{array}$ \\
\hline \multicolumn{9}{|c|}{ Glucose and energy metabolism } \\
\hline 1066 & $\begin{array}{l}\text { Mitochondrial succinate dehydrogenase } \\
\text { complex subunit A (Sus scrofa) }\end{array}$ & SDHA & gil112980819 & 134 & 54812 & 7.62 & Mitochondrion & Tricarboxylic acid cycle \\
\hline \multirow{2}{*}{\multicolumn{9}{|c|}{$\begin{array}{l}\text { Immune response } \\
\text { Ime-1, }\end{array}$}} \\
\hline & & & & & & & & \\
\hline 539 & $\lg \gamma-3$ chain $C$ region (Sus scrofa) & IGHG3 & gil164507 & 106 & 51088 & $6 \cdot 71$ & Extracellular region & Immune response \\
\hline 1435 & Ig $\gamma-4$ chain $\mathrm{C}$ region (Sus scrofa) & IGHG4 & gil2136516 & 145 & 30898 & 8.68 & Extracellular region & Immune response \\
\hline 1493 & $\lg \gamma-3$ chain $\mathrm{C}$ region (Sus scrofa) & IGHG3 & gil164507 & 133 & 51088 & 6.71 & Extracellular region & Immune response \\
\hline 2019 & $\lg \gamma-2 B$ chain $C$ region (Sus scrofa) & IGHG2B & gil2136514 & 83 & 35959 & 8.46 & Secreted; Cell membrane & immune response \\
\hline \multicolumn{9}{|c|}{ Gene expression and protein metabolism } \\
\hline 3928 & $\begin{array}{l}\text { Eukaryotic translation initiation factor } 5 \mathrm{~A}-1 \\
\text { (Homo sapiens) }\end{array}$ & EIF5A & gil183448388 & 81 & 15140 & $5 \cdot 80$ & $\begin{array}{l}\text { Endoplasmic reticulum } \\
\text { membrane }\end{array}$ & Positive regulation of cell proliferation \\
\hline 2740 & $\begin{array}{l}\text { Eukaryotic translation initiation factor } 6 \\
\text { (Ovis aries) }\end{array}$ & EIF6 & gil242247423 & 86 & 26496 & 4.61 & & $\begin{array}{l}\text { Protein biosynthesis; mature ribosome } \\
\text { assembly }\end{array}$ \\
\hline 600 & $\begin{array}{l}\text { Eukaryotic translation elongation factor } 2 \\
\text { (Canis familiaris) }\end{array}$ & EEF2 & gil73987435 & 123 & 77834 & $6 \cdot 34$ & Cytoplasm & Translational elongation \\
\hline 2091 & $\begin{array}{l}\text { Serine/threonine kinase receptor-associated } \\
\text { protein (Homo sapiens) }\end{array}$ & STRAP & gil148727341 & 107 & 38414 & 4.98 & Cytoplasm & mRNA processing; mRNA splicing \\
\hline 211 & $\begin{array}{l}\text { Carbamoyl-phosphate synthetase } 1 \\
\text { mitochondrial (Canis familiaris) }\end{array}$ & CPS1 & gil74005363 & 116 & 165010 & $6 \cdot 10$ & Mitochondrion & Glutamine metabolic process \\
\hline \multicolumn{9}{|c|}{ Redox homoeostasis and stress response } \\
\hline 2965 & $\begin{array}{l}\text { Peroxiredoxin } 1 \text { (Cricetulus griseus) } \\
\quad(E C \text { 1.11.1.15) }\end{array}$ & PRDX1 & gil81917543 & 99 & 22248 & $8 \cdot 22$ & Cytoplasm & Cell redox homoeostasis \\
\hline 3967 & Peroxiredoxin 5 (Sus scrofa) & PRDX5 & gil47523086 & 157 & 17313 & $5 \cdot 71$ & Cytoplasm & Cell redox homoeostasis \\
\hline 1385 & Catalase (Sus scrofa) & CAT & gil50979303 & 107 & 57277 & $6 \cdot 26$ & Peroxisome & Cell redox homoeostasis \\
\hline 775 & $\begin{array}{l}\text { Heat-shock protein } 90-\mathrm{kDa} \text { a (cytosolic), } \\
\text { class A member } 1 \text { (Homo sapiens) }\end{array}$ & HSP90AA1 & gil62914009 & 188 & 73780 & 5.08 & Cytoplasm & Response to stress \\
\hline 893 & $\begin{array}{l}78 \text { kDa glucose-regulated protein } \\
\text { (Canis familiaris) }\end{array}$ & GRP78 & gil73968066 & 127 & 65324 & $5 \cdot 11$ & Endoplasmic reticulum & Response to stress \\
\hline 1100 & Heat shock $70 \mathrm{kDa}$ protein $1 \mathrm{~B}$ (Sus scrofa) & HSPA1B & gil47523308 & 165 & 70055 & $5 \cdot 60$ & Cytoplasm & Response to stress \\
\hline \multicolumn{9}{|c|}{ Cell proliferation and apoptosis } \\
\hline 3638 & Calmodulin (Homo sapiens) & CALM & gil114677917 & 74 & 29312 & 4.76 & Cytoplasm & Regulation of cytokinesis \\
\hline 2460 & Annexin A4 (Sus scrofa) & ANXA4 & gil264681432 & 145 & 35806 & $5 \cdot 71$ & Cytoplasm & $\begin{array}{l}\text { Negative regulation of apoptosis; } \\
\text { epithelial cell differentiation; } \\
\text { Ca ion binding }\end{array}$ \\
\hline 1710 & Lactadherin (Sus scrofa) & MFGE8 & gil172072653 & 155 & 47819 & $6 \cdot 27$ & Extracellular space & $\begin{array}{l}\text { Cell adhesion; positive regulation of } \\
\text { phagocytosis }\end{array}$ \\
\hline $\begin{array}{l}1514 \\
2436\end{array}$ & $\begin{array}{l}\text { Calreticulin (Sus scrofa) } \\
\text { Annexin A5 (Homo sapiens) }\end{array}$ & $\begin{array}{l}\text { CALR } \\
\text { ANXA5 }\end{array}$ & $\begin{array}{l}\text { gil291622246 } \\
\text { gil4502107 }\end{array}$ & $\begin{array}{r}130 \\
97\end{array}$ & $\begin{array}{l}48258 \\
35914\end{array}$ & $\begin{array}{l}4.32 \\
4.94\end{array}$ & $\begin{array}{l}\text { Endoplasmic reticulum lumen } \\
\text { Cytoplasm }\end{array}$ & $\begin{array}{l}\text { Cell cycle arrest } \\
\text { Apoptosis; signal transduction }\end{array}$ \\
\hline
\end{tabular}

MW, molecular weight; pl, isoelectric point.

Spot numbers refer to protein spot numbers that correspond to the labels in Fig. 2 and 3.

$\dagger$ Protein score generated by MS identification platform, with a score over seventy-one being considered as statistical significance $(P<0.05)$. 


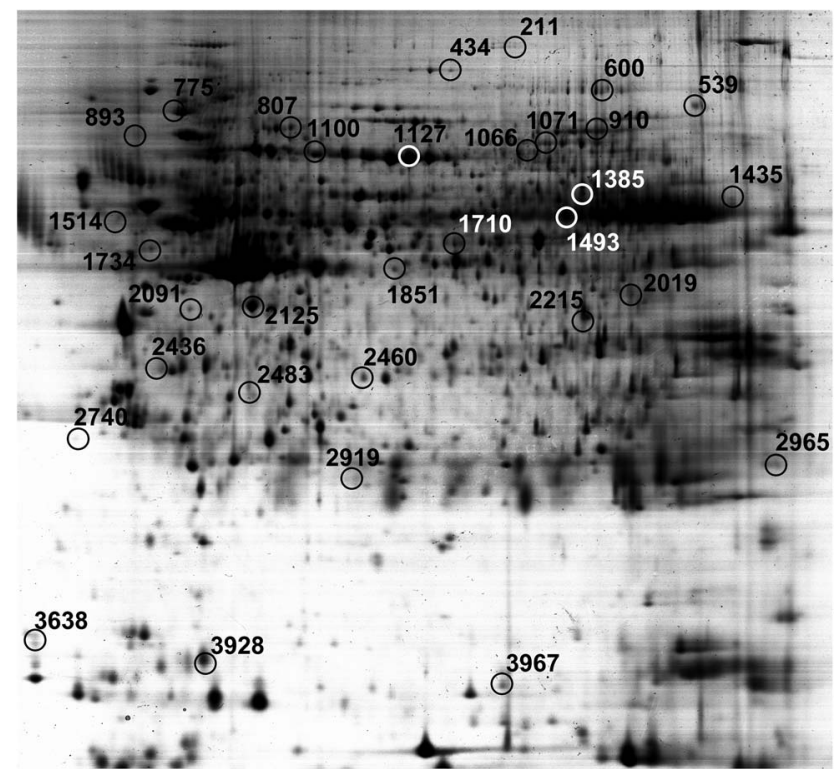

Fig. 2. Distribution of differentially expressed jejunal proteins between porcine intra-uterine growth restriction and normal-birth weight neonates at days 0 and 1 in the two-dimensional gel.

neonates as compared with the NBW group; however, no difference $(P>0.05)$ in the abundance of IGHG2B was observed between IUGR and NBW groups. After colostrum intake, both IUGR and NBW neonates exhibited increases $(P<0.05)$ in IGHG3 and IGHG4 with a lesser extent in the IUGR jejunal mucosa, as evidenced by their lower $(P<0.05)$ abundance in IUGR than NBW at D1. Furthermore, colostrum feeding increased $(P<0.05)$ IGHG2B in NBW jejunal mucosa at D1, but it did not affect $(P>0.05)$ its abundance in the IUGR group between D0 and D1.

\section{Protein metabolism}

Five spots of proteins were related to protein metabolism (synthesis and degradation) (Fig. 3(e)). They are eukaryotic translation initiation factor 5A-1 (EIF5A; Spot 3928), eukaryotic translation initiation factor 6 (EIF6; Spot 2740), eukaryotic translation elongation factor 2 (EEF2; Spot 600), serine/threonine kinase receptor-associated protein (STRAP; Spot 2091) and mitochondrial carbamoyl-phosphate synthetase 1 (CPS1; Spot 211). At $d$ 0, the abundances of EIF5A, EIF6 and STRAP were lower $(P<0.05)$ in the jejunal mucosa of IUGR as compared with the NBW group, whereas the abundance of CPS1 was higher $(P<0.05)$ in the IUGR group. However, no difference $(P>0.05)$ in EEF2 was detected between IUGR and NBW groups. At d 1, the abundance of EEF2 was lower $(P<0.05)$ in the jejunal mucosa of IUGR neonates as compared with the NBW group, whereas the abundance of CPS1 was still higher $(P<0.05)$ in IUGR piglets. However, no differences in EIF5A, EIF6 and STRAP were observed between IUGR and NBW groups. When compared between D0 and D1, colostrum consumption increased $(P<0.05)$ the abundances of EIF5A, EIF6 and EEF2, but decreased $(P<0.05)$ CPS1 in both IUGR and NBW neonates. In addition, the abundance of STRAP was increased $(P<0.05)$ by colostrum intake in IUGR piglets but remained at the same level in NBW neonates at D1 as compared with D0.

\section{Redox homoeostasis and stress response}

Six spots of proteins were associated with redox homoeostasis and stress response (Fig. 3(f)). They are peroxiredoxin 1 (PRDX1; Spot 2965), peroxiredoxin 5 (PRDX5; Spot 3967), catalase (CAT; Spot 1385), heat shock protein $90 \mathrm{kDa} \alpha$, class A member 1 (HSP90AA1; Spot 775), 78-kDa GRP78 (Spot 893) and heat shock $70 \mathrm{kDa}$ protein 1B (HSPA1B; Spot 1100). At D0, the abundances of PRDX1, PRDX5, HSP90AA1 and GRP78 were higher $(P<0.05)$ in the jejunal mucosa of IUGR neonates as compared with the NBW group; however, no differences in CAT and HSPA1B were observed between IUGR and NBW groups. At d 1, PRDX1, PRDX5, CAT, HSP90AA1, GRP78 and HSPA1B were higher $(P<0.05)$ in the IUGR group as compared with the NBW group. When compared between D0 and D1, colostrum intake decreased $(P<0.05)$ the abundances of PRDX1, PRDX5, CAT, HSP90AA1, GRP78 and HSPA1B in both IUGR and NBW groups, and the decrease occurred to a lesser extent in the IUGR group.

\section{Cell proliferation and apoptosis}

Five spots of proteins were related to cell proliferation and apoptosis (Fig. 3(g)). They are calmodulin (CALM; Spot 3638), annexin A4 (ANXA4; Spot 2460), lactadherin (milk fat globuleEGF factor 8 protein (MFGE8); Spot 1710), calreticulin (CALR; Spot 1514) and annexin A5 (ANXA5; Spot 2436). At D0, the abundance of ANXA4 was lower $(P<0.05)$ in the jejunal mucosa of IUGR neonates as compared with those in the NBW group, whereas the abundance of ANXA5 was higher $(P<0.05)$ in IUGR neonates. However, no differences in CALM, MFGE8 and CALR were detected between IUGR and NBW groups. At D1, compared with the jejunal mucosa of NBW neonates, the abundances of CALM and MFGE8 were lower $(P<0.05)$ in the IUGR group, whereas the abundances of CALR and ANAX5 were higher $(P<0.05)$ in the IUGR group. However, no differences $(P>0.05)$ in ANXA4 were detected between the IUGR and NBW groups. When compared between D0 and D1, colostrum ingestion increased $(P<0.05)$ the abundance of MFGE8, but decreased $(P<0.05)$ the abundances of CALR and ANXA5 in both IUGR and NBW groups. Moreover, colostrum feeding increased $(P<0.05)$ the abundance of CALM in NBW piglets but decreased $(P<0.05)$ that of CALM in the IUGR group. Although ANXA4 was maintained at the same level $(P>0.05)$ in NBW piglets at D1, colostrum intake increased $(P<0.05)$ the abundance of ANXA4 in the jejunal mucosa of IUGR neonates.

\section{Functional annotation and upstream regulator analyses}

The top pathways that changed in the aberrantly regulated protein list included (1) cell death and survival; (2) synthesis of nitric oxide (NO); (3) endocytosis; (4) cellular movement; (5) free-radical scavenging; (6) inflammatory response; and (7) protein synthesis and phosphorylation (Table 2) according to IPA software. The top upstream regulator affected (activated or inhibited) included transporter (ALB), transcription regulators (CALR, HNF4A, MYC, NFE2L2, TP53, XBP1), growth factor (ANGPT2), cytokines (IL-4, 
(a) Spot 1127: ALB
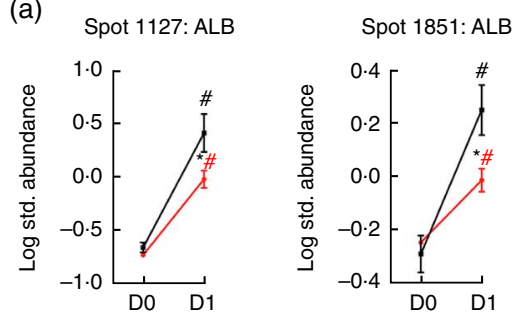

(b) Spot 1071: LMNA
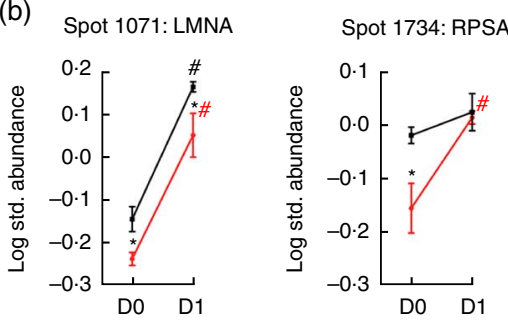

(d) Spot 539: IGHG3
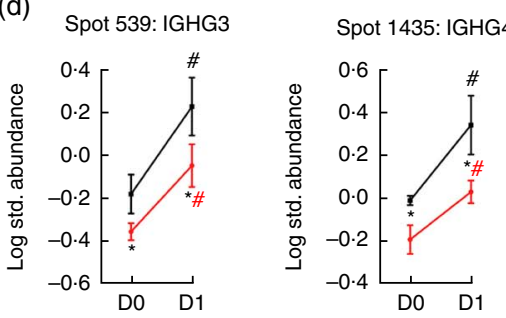

(e)

Spot 3928: EIF5A
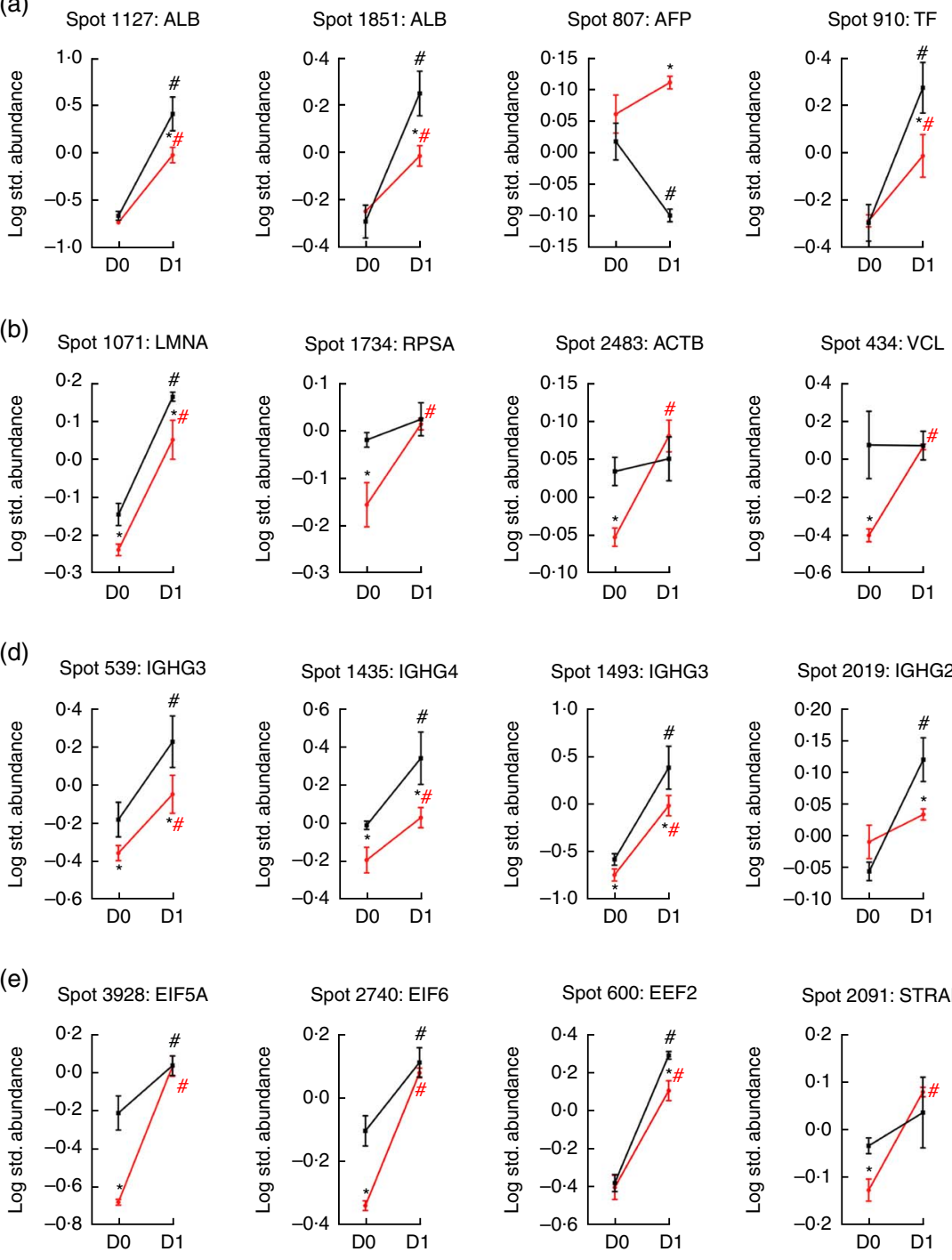

(f) Spot 2965: PRDX1
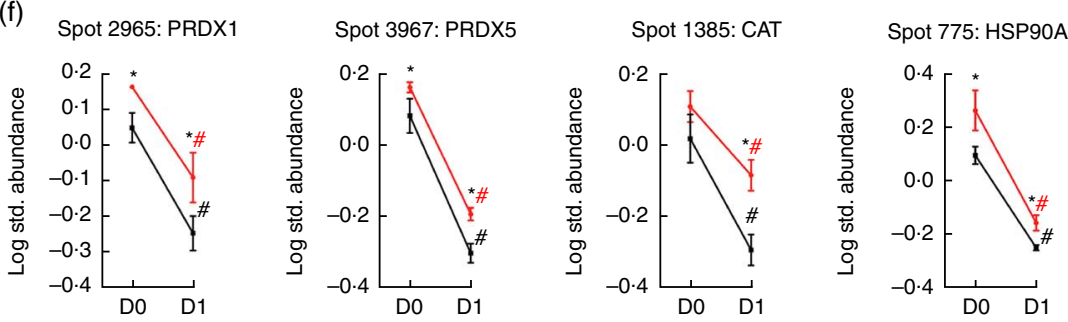

(g) Spot 3638: CALM
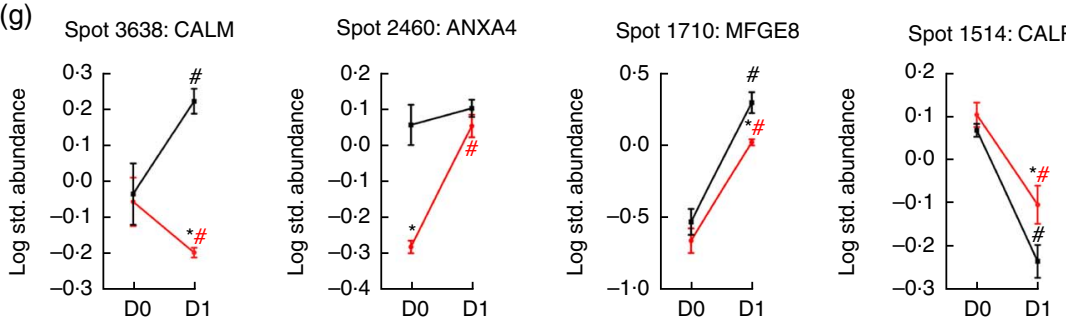

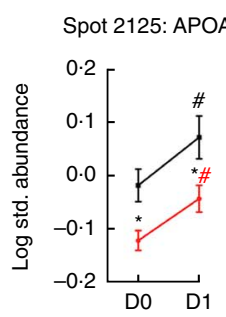

(c) Spot 1066: SDHA

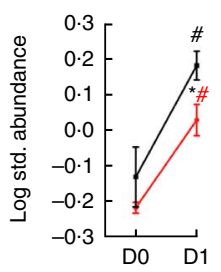

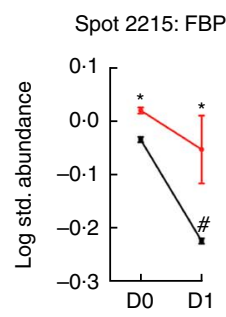


prolactin), chemical reagents (1,2-dithiol-3-thione, cycloheximide), chemical drugs (bortezomib, gentamicin, phorbol myristate acetate, sirolimus, valproic acid, $\beta$-oestradiol) and other (LMNA) (Table 3). The entire list of functional annotation and upstream regulators can be found as the online Supplementary Tables 1 and 2.

\section{Validation of proteomic data by Western blotting}

Fig. 4 shows the Western blot analysis of 4 proteins (ACTB, TF, GRP78 and ALB) randomly selected from Table 1 for validation of proteomic data. The Western blotting results were consistent with the findings from the temporal proteomic analysis.

\section{Discussion}

IUGR predisposes offspring to malfunction and delayed development of multiple organs, including the gut, liver and skeletal muscles ${ }^{(1,4,6,26-28)}$. Of particular interest, previous studies have demonstrated marked alterations of the jejunal proteome in IUGR piglets after birth and its continuous impairment during the nursing period ${ }^{(6,8)}$. Further studies have also revealed a significant change of the jejunal mucosal proteins in IUGR fetuses during mid-gestation to late gestation, which are associated with gut growth, development and reprogramming ${ }^{(7)}$. However, innate differences in intestinal proteome between IUGR and NBW neonates (IUGR $v$. NBW at D0), as well as associated alterations in response to colostrum ingestion within $24 \mathrm{~h}$ after birth (D1 $v$. D0 in IUGR; D1 $v$. D0 in NBW; IUGR $v$. NBW at D1), remain largely unknown. At birth, the neonates undergo rapid transitions from a sterile uterine environment with a continuous intravenous supply of nutrients to a microbe-rich environment with intermittent ingestion of colostrum first and then milk nutrients via the gut ${ }^{(29,30)}$. The growth differences between IUGR and NBW after $24 \mathrm{~h}$ of colostrum ingestion may account for the amount of colostrum intake and/or defects in the postnatal development of IUGR jejunum, and both were the causes of IUGR. Therefore, we investigated the differences in intestinal protein expression between IUGR and NBW piglets before or after ingesting colostrum. To our knowledge, results of the current study indicate, for the first time, postnatal acute changes of the intestinal proteome in IUGR neonates in response to colostrum consumption.

As innate difference, jejunal epithelium of IUGR piglets at birth exhibited increased inflammation, which reduced cell viability, as well as its function, such as cell invasion and endocytosis. Colostrum intake within $24 \mathrm{~h}$ decreased reactive oxygen species (ROS), inflammation and necrosis, whereas it increased protein synthesis, cell viability (proliferation, migration and invasion) and immune response, thereby increasing colony formation of cells in both IUGR and NBW neonatal jejunum. Specifically, colostrum increased the synthesis of NO and phosphorylation of proteins in NBW instead of IUGR neonatal jejunum, indicating the increased metabolism of amino acids such as glutamine, arginine and citrulline, as well as NO signalling such as angiogenesis. After $24 \mathrm{~h}$ of colostrum intake, jejunal epithelium of IUGR piglets remained higher cell death rate, ROS level and inflammation status, as well as lower cell viability and endocytosis, as compared with NBW neonates, suggesting that colostrum only alleviates but does not eliminate the disadvantageous states of IUGR jejunum.

ALB functions as the transporter of lipid-soluble molecules, such as steroid hormones, free fatty acids and $\mathrm{Ca}$ between blood circulation and target tissues, whereas TF serves as an Fe-binding protein in which Fe can be transported from sites of absorption and haeme degradation to tissues for storage and/or utilisation. Colostrum is rich in both ALB and TF, which exhibited low level at birth and increased at D1 in both IUGR and NBW jejunal epithelia, suggesting their accumulation via endocytosis rather than de novo synthesis within $24 \mathrm{~h}$ of colostrum intake. However, at D1, ALB and TF were lower in IUGR intestine as compared with the NBW group, indicating defects in epithelial function such as endocytosis. AFP (the fetal form of ALB), which usually degrades rapidly after birth, remained at a high level in IUGR neonates at D1, suggesting that colostrum-triggered divergent effects on the function (e.g. endocytosis and transport of nutrients) of the jejunum between IUGR and NBW piglets.

Milk or colostrum-borne cholesterol is crucial for development of the brain and insulin-sensitive tissue of neonates ${ }^{(31)}$. APOA4 is a major apoprotein ${ }^{(32)}$ that acts primarily in intestinal lipid absorption ${ }^{(33-35)}$. Intestinal fat absorption markedly increases the synthesis and secretion of APOA $4^{(36,37)}$, particularly in the jejunum (the major site of lipid absorption) ${ }^{(38)}$. In this study, both IUGR and NBW intestinal APOA4 increased in response to colostrum intake; however, the elevation was less efficient in IUGR jejunal mucosa, as evidenced by the consistently lower level of APOA4 in the IUGR group as compared with the NBW group.

LMNA, RPSA, ACTB and VCL are proteins that are involved in cell motility and integrity. LMNA (an intermediate filament) and ACTB (a non-muscle cytoskeletal actin) provide structural

Fig. 3. Quantification of temporal differentially expressed proteins of various cellular processes in the jejunum of porcine intra-uterine growth restriction (IUGR, - - ) and normal-birth weight (NBW, - neonates between Days 0 (D0) and 1 (D1) after birth. On the basis of biological functions, these proteins are classified into several groups: (a) transport of nutrients; (b) cell structure and motility; (c) glucose and energy metabolism; (d) immune response; (e) protein metabolism; (f) redox homoeostasis and stress response; and $(\mathrm{g})$ cell proliferation and apoptosis. Values are means ( $n 6$ for each group at D0 and D1), with their standard errors. ALB, albumin; AFP, a-fetoprotein; TF, transferrin; LMNA, lamin A/C; RPSA, laminin receptor 1 ; ACTB, $\beta$-actin; VCL, vinculin; SDHA, succinate dehydrogenase complex

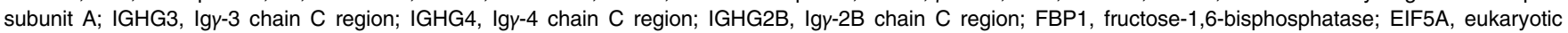
translation initiation factor $5 \mathrm{~A}-1$; EIF6, eukaryotic translation initiation factor 6 ; EEF2, eukaryotic translation elongation factor 2; STRAP, serine/threonine kinase receptor-associated protein; CPS1, carbamoyl-phosphate synthetase 1; PRDX1, peroxiredoxin 1; PRDX5, peroxiredoxin 5; CAT, catalase; HSP90AA1, heat shock protein $90 \mathrm{kDa}$ a, class A member 1; GRP78, glucose-regulated protein; HSPA1B, heat shock 70 kDa protein 1B; CALM, calmodulin; ANXA4, annexin A4; MFGE8, milk fat globule-EGF factor 8 protein; CALR, calreticulin; ANXA5, annexin A5. * Significant differences between IUGR and NBW groups at the same time point (either at D0 or D1). \# Significant differences $(P<0.05)$ between D0 and D1 in the same group (either IUGR or NBW). The spot numbers of the identified proteins are the same as those described in Table 1. 


\section{N British Journal of Nutrition}

Table 2. Functional annotation of differentially expressed proteins in the jejunual mucosa of intra-uterine growth restriction (IUGR) and normal-birth weight (NBW) neonates (days 0 (D0) and 1 (D1))

\begin{tabular}{|c|c|c|c|c|c|c|c|c|c|c|c|c|}
\hline \multirow[b]{2}{*}{ Diseases or functions annotations } & \multicolumn{3}{|c|}{ IUGR $v$. NBW at DO } & \multicolumn{3}{|c|}{ IUGR $v$. NBW at D1 } & \multicolumn{3}{|c|}{ D1 v. D0 in IUGR } & \multicolumn{3}{|c|}{ D1 v. D0 in NBW } \\
\hline & $P$ & $\begin{array}{c}\text { Activation } \\
z \text { score }\end{array}$ & Molecules & $P$ & $\begin{array}{c}\text { Activation } \\
z \text { score }\end{array}$ & Molecules & $P$ & $\begin{array}{c}\text { Activation } \\
z \text { score }\end{array}$ & Molecules & $P$ & $\begin{array}{c}\text { Activation } \\
z \text { score }\end{array}$ & Molecules \\
\hline \multicolumn{13}{|c|}{ Cancer, cell death and survival, organismal injury and abnormalities, tumour morphology } \\
\hline Apoptosis of tumour cells & & & & $2 \cdot 95 \mathrm{E}-04$ & 1.98 & 4 & $6 \cdot 13 \mathrm{E}-04$ & -1.98 & 4 & $7 \cdot 20 \mathrm{E}-04$ & -1.98 & 4 \\
\hline Cell death of cancer cells & & & & & & & $2 \cdot 24 \mathrm{E}-03$ & -1.26 & 4 & $2 \cdot 62 \mathrm{E}-03$ & -1.26 & 4 \\
\hline Cell death of tumour cells & & & & & & & $5 \cdot 03 E-04$ & -1.52 & 5 & $6 \cdot 14 \mathrm{E}-04$ & -1.52 & 5 \\
\hline \multicolumn{13}{|l|}{ Cell cycle, gene expression } \\
\hline Binding of DNA & $3.99 E-04$ & $1 \cdot 80$ & 5 & & & & & & & & & \\
\hline \multicolumn{13}{|l|}{ Cell death and survival } \\
\hline Apoptosis & & & & $2.50 E-04$ & 1.78 & 11 & $2 \cdot 54 \mathrm{E}-07$ & $-2 \cdot 16$ & 16 & $5.86 \mathrm{E}-07$ & $-2 \cdot 20$ & 16 \\
\hline $\begin{array}{l}\text { Apoptosis of prostate cancer } \\
\text { cell lines }\end{array}$ & & & & & & & $9 \cdot 39 E-05$ & -1.93 & 4 & $1 \cdot 11 E-04$ & -1.93 & 4 \\
\hline Apoptosis of tumour cell lines & & & & & & & $5 \cdot 56 \mathrm{E}-04$ & -1.37 & 8 & $1 \cdot 28 \mathrm{E}-04$ & -1.37 & 9 \\
\hline Cell death & & & & $1.93 E-06$ & 1.38 & 15 & $7 \cdot 30 E-11$ & -2.09 & 21 & $4.86 \mathrm{E}-09$ & -1.82 & 20 \\
\hline Cell death of brain & & & & $3.74 \mathrm{E}-04$ & 1.92 & 4 & $7.75 E-04$ & -1.92 & 4 & $9 \cdot 10 E-04$ & -1.92 & 4 \\
\hline $\begin{array}{l}\text { Cell death of central nervous } \\
\text { system cells }\end{array}$ & & & & & & & & & & $6 \cdot 80 \mathrm{E}-05$ & -1.46 & 5 \\
\hline Cell death of tumour cell lines & & & & $1.07 \mathrm{E}-04$ & 1.26 & 9 & $1.47 \mathrm{E}-05$ & -1.29 & 11 & $3.25 E-06$ & -1.29 & 12 \\
\hline Cell survival & & & & & & & $7 \cdot 14 \mathrm{E}-07$ & 2.51 & 12 & & & \\
\hline Cell viability & $7.79 E-03$ & -1.74 & 6 & $2.44 \mathrm{E}-04$ & $-2 \cdot 40$ & 8 & 3.36E -06 & 2.94 & 11 & $4.05 E-05$ & $2 \cdot 77$ & 10 \\
\hline Cell viability of tumour cell lines & & & & $6 \cdot 25 E-04$ & -1.99 & 6 & $2 \cdot 66 \mathrm{E}-04$ & $2 \cdot 22$ & 7 & $2 \cdot 24 \mathrm{E}-03$ & 1.99 & 6 \\
\hline Cytolysis & & & & & & & $2.94 E-05$ & -1.43 & 5 & $3.62 E-05$ & -1.43 & 5 \\
\hline Necrosis & & & & $4.85 E-05$ & $2 \cdot 10$ & 12 & $3.43 E-08$ & $-2 \cdot 20$ & 17 & $8.84 \mathrm{E}-08$ & $-2 \cdot 48$ & 17 \\
\hline Neuronal cell death & & & & $1 \cdot 15 \mathrm{E}-02$ & 1.80 & 4 & & & & & & \\
\hline \multicolumn{13}{|c|}{ Cell death and survival, organismal injury and abnormalities } \\
\hline Cell death of epithelial cells & & & & & & & $6.62 \mathrm{E}-03$ & -1.96 & 4 & & & \\
\hline Apoptosis of kidney cell lines & & & & & & & $3 \cdot 21 \mathrm{E}-04$ & -1.98 & 4 & $3.78 \mathrm{E}-04$ & -1.98 & 4 \\
\hline Cell death of kidney cells & & & & & & & $1.46 \mathrm{E}-04$ & -1.98 & 5 & $1.79 E-04$ & -1.98 & 5 \\
\hline \multicolumn{13}{|c|}{ Cell signalling, small-molecule biochemistry } \\
\hline Synthesis of nitric oxide & & & & & & & & & & $4 \cdot 60 E-05$ & $1 \cdot 21$ & 5 \\
\hline \multicolumn{13}{|l|}{ Cell-to-cell signalling and interaction } \\
\hline Activation of cells & & & & & & & & & & $4.59 E-03$ & 1.45 & 6 \\
\hline Binding of tumour cell lines & & & & & & & $2.54 \mathrm{E}-03$ & 1.99 & 4 & & & \\
\hline \multicolumn{13}{|c|}{ Cellular development, cellular growth and proliferation } \\
\hline $\begin{array}{l}\text { Cell proliferation of tumour cell } \\
\text { lines }\end{array}$ & & & & & & & $8 \cdot 43 E-04$ & 1.42 & 9 & $1 \cdot 18 \mathrm{E}-03$ & $2 \cdot 04$ & 9 \\
\hline \multicolumn{13}{|l|}{ Cellular function and maintenance } \\
\hline Cellular homoeostasis & & & & $4.24 \mathrm{E}-03$ & -1.38 & 7 & $6 \cdot 80 \mathrm{E}-04$ & 1.38 & 9 & $1.84 \mathrm{E}-04$ & 1.65 & 10 \\
\hline Endocytosis & & & & $2 \cdot 70 E-03$ & -1.95 & 4 & $6.48 \mathrm{E}-04$ & $2 \cdot 19$ & 5 & $7.97 \mathrm{E}-05$ & $2 \cdot 39$ & 6 \\
\hline Endocytosis by eukaryotic cells & $4 \cdot 29 E-04$ & -1.21 & 4 & & & & $8.88 \mathrm{E}-04$ & 1.94 & 4 & $7.97 \mathrm{E}-05$ & $2 \cdot 17$ & 5 \\
\hline Engulfment of cells & & & & & & & $3.87 \mathrm{E}-04$ & 1.53 & 5 & $4 \cdot 25 E-05$ & 1.76 & 6 \\
\hline \multicolumn{13}{|l|}{ Cellular growth and proliferation } \\
\hline Colony formation of cells & & & & & & & $1.00 E-04$ & $2 \cdot 20$ & 6 & $1 \cdot 28 \mathrm{E}-04$ & $2 \cdot 20$ & 6 \\
\hline \multicolumn{13}{|l|}{ Cellular movement } \\
\hline Cell movement & & & & & & & & & & $2 \cdot 56 \mathrm{E}-03$ & $1 \cdot 30$ & 10 \\
\hline Invasion of cells & $1.03 E-03$ & $-1 \cdot 21$ & 6 & & & & $4.75 E-04$ & 1.72 & 7 & $3.61 E-03$ & 1.53 & 6 \\
\hline Migration of cells & & & & & & & $1.29 \mathrm{E}-04$ & 1.27 & 11 & $4.08 E-03$ & 1.53 & 9 \\
\hline
\end{tabular}




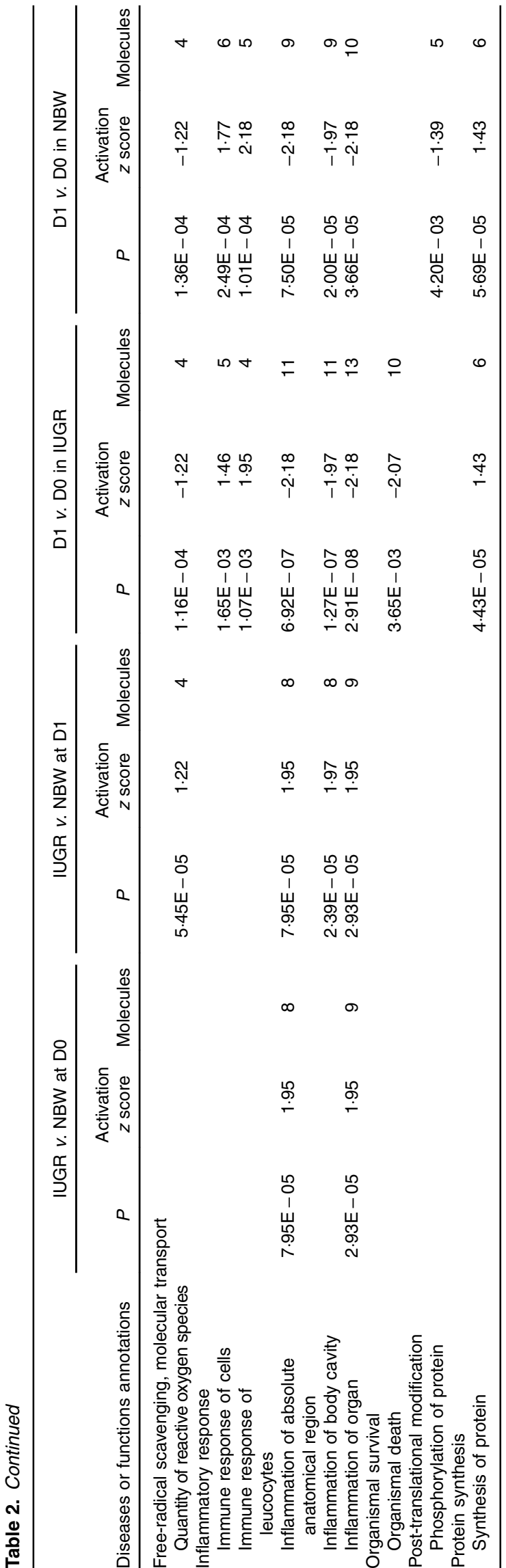

function and transcriptional regulation in the cell, whereas RPSA and VCL play vital roles in cell adhesion and migration. In this study, lower abundances of LMNA, RPSA, ACTB and VCL indicate defects in the structure and motility of jejunal epithelial cells in IUGR neonates after birth ${ }^{(39)}$. However, colostrum intake increases cell migration and invasion of both IUGR and NBW jejunal epithelia.

Glucose is utilised for ATP production by the porcine fetal/neonatal small intestine and is the major source of NADPH for synthetic processes. After colostrum ingestion for $24 \mathrm{~h}$, SDHA served in the Krebs cycle increased in both IUGR and NBW groups, indicating the increased utilisation of colostrumderived glucose for ATP production in the jejunal mucosa. However, IUGR jejunal mucosa responded less to colostrum feeding, as evidenced by a smaller elevation of SDHA. At birth, the transplacental transfer of substrates is terminated, and the neonates must produce their own glucose, particularly for the needs of the central nervous system, before their access to colostrum/milk (e.g. lactose). FBP1 functions as the rate-limiting enzyme in gluconeogenesis that catalyses the hydrolysis of fructose 1,6-biphosphate to fructose 6-phosphate. IUGR neonates displayed inherently higher levels of FBP1 than NBW neonates, which account for the mechanism to compensate for the reduced rate of glucose production prenatally in the IUGR jejunal mucosa. Interestingly, such high levels of FBP1 were maintained in IUGR jejunal mucosa even after the colostrum was provided, suggesting the innate defects and deficiency in the absorption and/or utilisation of colostrumderived glucose.

Colostrum is also rich in Ig (primarily IgG), which is vastly reduced $24 \mathrm{~h}$ after birth. These antibodies in the colostrum are absorbed via pinocytosis by epithelial cells in the small intestine, particularly in the jejunum and ileum, providing immunity to the newborns. Such passive immunity transfer by means of ingestion and absorption of the colostrum is even more critical for newborn piglets because the porcine epitheliochorial placenta prevents intra-uterine passage of maternal antibodies to the fetus. An important finding of this study is that colostrum ingestion enhances the immunity of neonates, as evidenced by elevation of IgG in both IUGR and NBW jejunal mucosa, whereas IUGR impairs the efficiency in such colostrum-triggered elevation, which indicates that IUGR jeopardises the ability of neonates to absorb intact IgG before gut closure.

EIF5A, EIF6, EEF2 and STRAP play important roles in protein anabolism, whereas CPS1 is involved in protein catabolism. Altered expression of these proteins has not previously been reported for IUGR neonates. Specifically, EIF5A and EIF6 are related to the initiation of mRNA translation, thereby positively regulating cell proliferation ${ }^{(40-42)}$. Similarly, EEF2, as an important component of EFF required for the elongation stage of mRNA translation, is essential for protein synthesis ${ }^{(43)}$. STRAP plays a role in the cellular distribution of the survival of motor neurons complex, which mediates the biogenesis of spliceosomal small nuclear ribonucleoproteins. As key regulators for mRNA translation, lower abundances of EIF5A, EIF6 and STRAP may be indicative of lower protein synthesis rates in the jejunal mucosa of IUGR neonates at birth as compared with the 
Table 3. Upstream regulators of differentially expressed proteins in the jejunual mucosa of intra-uterine growth restriction (IUGR) and normal-birth weight (NBW) neonates (days 0 (D0) and 1 (D1))

\begin{tabular}{|c|c|c|c|c|c|c|c|c|c|c|c|c|c|}
\hline \multirow[b]{3}{*}{ Molecule types } & \multirow[b]{3}{*}{$\begin{array}{l}\text { Upstream } \\
\text { regulator }\end{array}$} & \multicolumn{3}{|c|}{ Innate difference } & \multicolumn{3}{|c|}{ Colostrum effects } & \multicolumn{3}{|c|}{ Colostrum effects } & \multicolumn{3}{|c|}{ Differential effects by colostrum } \\
\hline & & \multicolumn{3}{|c|}{ IUGR $v$. NBW at D0 } & \multicolumn{3}{|c|}{ D1 v. D0 IUGR } & \multicolumn{3}{|c|}{ D1 v. D0 NBW } & \multicolumn{3}{|c|}{ IUGR $v$. NBW at D1 } \\
\hline & & $\begin{array}{l}\text { Expr fold } \\
\text { change }\end{array}$ & $\begin{array}{l}\text { Activation } \\
z \text { score }\end{array}$ & $\begin{array}{l}\text { Overlap } \\
(P)\end{array}$ & $\begin{array}{l}\text { Expr fold } \\
\text { change }\end{array}$ & $\begin{array}{l}\text { Activation } \\
z \text { score }\end{array}$ & $\begin{array}{l}\text { Overlap } \\
\qquad(P)\end{array}$ & $\begin{array}{l}\text { Expr fold } \\
\text { change }\end{array}$ & $\begin{array}{l}\text { Activation } \\
z \text { score }\end{array}$ & $\begin{array}{l}\text { Overlap } \\
(P)\end{array}$ & $\begin{array}{l}\text { Expr fold } \\
\text { change }\end{array}$ & $\begin{array}{l}\text { Activation } \\
z \text { score }\end{array}$ & $\begin{array}{l}\text { Overlap } \\
\quad(P)\end{array}$ \\
\hline Transporter & ALB & & & & $5 \cdot 35$ & & $1 \cdot 10 \mathrm{E}-03$ & 13.55 & & $1.19 E-03$ & -3.02 & & $7.61 \mathrm{E}-04$ \\
\hline Transcription regulator & CALR & $-2 \cdot 24$ & & $3 \cdot 84 \mathrm{E}-02$ & 3.35 & & $4.59 \mathrm{E}-02$ & & & & & & \\
\hline Transcription regulator & HNF4A & & & & & 1.43 & $1.27 \mathrm{E}-03$ & & & & & & \\
\hline Transcription regulator & MYC & & & & & -1.39 & $1.04 \mathrm{E}-03$ & & & & & & \\
\hline Transcription regulator & NFE2L2 & & & & & 1.93 & $1.07 \mathrm{E}-03$ & & $2 \cdot 15$ & $1.01 \mathrm{E}-04$ & & -1.93 & $5 \cdot 20 \mathrm{E}-04$ \\
\hline Transcription regulator & TP53 & & -1.45 & $2 \cdot 11 \mathrm{E}-03$ & & & & & & & & & \\
\hline Transcription regulator & XBP1 & & & & & & & & 1.21 & $9 \cdot 73 E-05$ & & & \\
\hline Growth factor & ANGPT2 & & & & & $2 \cdot 22$ & $1.95 \mathrm{E}-06$ & & 2.43 & $7.02 E-08$ & & & \\
\hline Cytokine & IL-4 & & & & & $2 \cdot 20$ & $2 \cdot 38 \mathrm{E}-03$ & & $2 \cdot 20$ & $2 \cdot 88 \mathrm{E}-03$ & & -1.96 & $7.64 \mathrm{E}-03$ \\
\hline Cytokine & Prolactin & & -1.45 & $1.05 E-04$ & & 1.45 & $2 \cdot 22 \mathrm{E}-04$ & & & & & & \\
\hline Chemical reagent & 1,2-Dithiol-3-thione & & & & & 1.97 & $7.79 E-05$ & & $2 \cdot 21$ & $3.68 E-06$ & & & \\
\hline Chemical reagent & Cycloheximide & & & & & & & & -1.72 & $8 \cdot 22 E-04$ & & & \\
\hline Chemical drug & Bortezomib & & & & & & & & 1.96 & $1.50 E-04$ & & & \\
\hline Chemical drug & Gentamicin & & & & & & & & 1.98 & $1.73 E-04$ & & & \\
\hline Chemical drug & $\begin{array}{l}\text { Phorbol myristate } \\
\text { acetate }\end{array}$ & & & & & $2 \cdot 14$ & $1 \cdot 38 \mathrm{E}-04$ & & 1.92 & $7 \cdot 60 \mathrm{E}-03$ & & & \\
\hline Chemical drug & Sirolimus & & & & & $-2 \cdot 40$ & $1.03 E-06$ & & $-2 \cdot 19$ & $2 \cdot 17 \mathrm{E}-05$ & & 1.96 & $8.77 E-05$ \\
\hline Chemical drug & Valproic acid & & & & & 1.93 & $1.48 \mathrm{E}-03$ & & 1.93 & $1.74 \mathrm{E}-03$ & & & \\
\hline $\begin{array}{l}\text { Chemical - endogenous } \\
\text { mammalian }\end{array}$ & $\beta$-Oestradiol & & $-1 \cdot 34$ & $4 \cdot 70 E-03$ & & 1.91 & $5 \cdot 10 E-04$ & & $1 \cdot 24$ & $6 \cdot 95 \mathrm{E}-04$ & & $-1 \cdot 24$ & $8 \cdot 24 E-04$ \\
\hline Other & LMNA & & & & & & & 2.04 & & $3 \cdot 12 \mathrm{E}-02$ & -1.28 & & $2.05 E-02$ \\
\hline
\end{tabular}

ALB, albumin; CALR, calreticulin; HNF4A, hepatocyte nuclear factor 4 alpha; MYC, MYC proto-oncogene; NFE2L2, nuclear factor, erythroid 2 like 2; TP53, tumour protein P53; XBP1, X-box binding protein 1; ANGPT2, angiopoietin-2; LMNA, lamin A/C. 
(A)

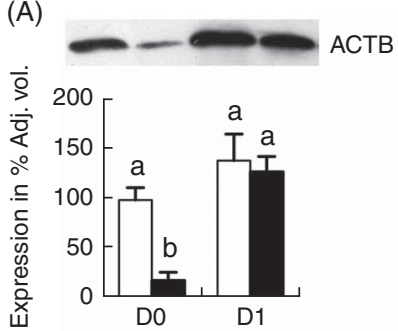

(C)

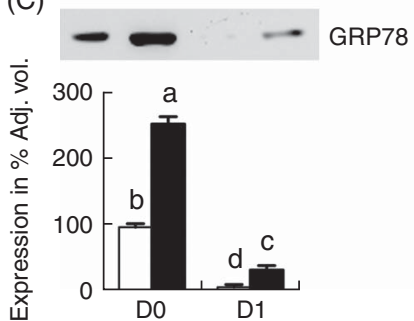

(B)

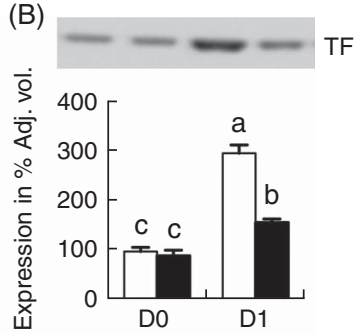

(D)

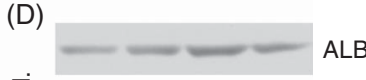

Fig. 4. Western blot analysis of jejunal mucosa proteins, $\beta$-actin (ACTB) (A), transferrin (TF) (B), glucose-regulated protein (GRP78) (C) and albumin (ALB) (D). Values are means ( $n 6$ for each group at days 0 (D0) and 1 (D1)), with their standard errors represented by vertical bars. $\square$, Normal-birth weight; $\square$, intrauterine growth restriction. $a, b, c, d$ Mean values with unlike letters were significantly different $(P<0.05)$ among groups.

NBW group. In general, ingested colostrum promotes protein synthesis in the jejunal mucosa of both IUGR and NBW neonates; however, such effects were less in jejunal epithelia of IUGR neonates. In addition, CPS1 functions in the synthesis of citrulline and thus arginine from glutamine, glutamate and proline in pig enterocytes to support piglet growth. This synthetic pathway is of nutritional importance as sow's milk is severely deficient in arginine ${ }^{(9)}$.

PRDX1 and PRDX2 belong to the ubiquitous family of antioxidant enzymes that participate in cellular redox regulation ${ }^{(44)}$. Similarly, CAT is a key antioxidant enzyme in cellular defense against oxidative stress. As compared with IUGR and NBW groups at D0, reduced abundance of PRDX1, PRDX2 and CAT suggests the beneficial effect of colostrum on ameliorating intestinal redox status in the jejunal mucosa of both groups after colostrum consumption ${ }^{(39)}$. Although quantities of ROS were reduced by colostrum intake, the abundances of PRDX1, PRDX2 and CAT remained consistently higher in IUGR piglets than in the NBW group. These results are in keeping with increased levels of intestinal HSP90AA1, GRP78 and HSPA1B in IUGR neonates, which are indicators of stress response ${ }^{(45-47)}$.

Appropriate cell turnover (proliferation, migration and apoptosis) is required for the maintenance of an intact epithelial layer in the gut. Another novel finding of this study is that IUGR affected cell viability of jejunal epithelia at birth, and colostrum can partially reverse but not eliminate such disadvantageous status whereby cell proliferation, migration and invasion were increased and apoptosis was decreased. CALM is a ubiquitous $\mathrm{Ca}^{2+}$ receptor protein ${ }^{(48)}$ required for cell proliferation $^{(49-51)}$. ANXA4 and ANXA5 belong to the multifunctional ANX family of proteins associated with the digestive system, in which ANXA4 induces a resistance to apoptosis

and ANXA5 is involved in the activation of cell death mechanisms ${ }^{(52-55)}$. MFGE8 regulates mucosal homoeostasis by modulating the mobility of intestinal epithelial cells ${ }^{(56)}$. Deficiency of MFGE8 leads to apoptotic cell accumulation ${ }^{(57)}$. CALR is a multi-functional protein that participates in cellular apoptosis ${ }^{(58,59)}$. The changes of these proteins (see Fig. 3(g)) suggest the following: (1) IUGR hinders cell growth and accelerates apoptosis of porcine neonatal jejunal mucosa at birth, and (2) colostrum consumption exhibits a protective effect on neonatal jejunal mucosa by promoting cell proliferation and diminishing apoptosis. Interestingly, an increase in the abundance of CALM in NBW piglets and a decrease in IUGR neonates indicate a divergent effect of colostrum consumption.

In summary, results of this study indicate innate differences and colostrum-induced alterations of the proteome in porcine jejunal mucosa between IUGR and NBW neonates. Specifically, the findings reveal increased levels of proteins and enzymes associated with oxidative stress, apoptosis and protein degradation, as well as decreased abundances of proteins required for maintenance of cell structure, motility and integrity, cell proliferation, transport of nutrients, energy metabolism and protein synthesis in the jejunal mucosa of IUGR neonates. However, compared with LC/MS-based proteomics, gel-based approaches can only detect proteins with relatively high abundance. Thus, some of the differentially expressed proteins with critical biological function, owing to their low abundance, may not be detected in this study. Collectively, these innate differences may be the major mechanisms responsible for intestinal growth arrest, atrophy and dysfunction in IUGR neonates, and alterations in response to colostrum intake help us gain insights into understanding the functional role of colostrum on gut development beneficial for both humans and animals.

\section{Acknowledgements}

Contributions of the graduate students and postdoctoral fellows from the State Key Laboratory of Animal Nutrition are gratefully acknowledged.

This present study was supported by the National Natural Science Foundation of China (nos 31272449, 31422052 and 31630074), the Beijing Municipal Natural Science Foundation (S170001), the National Key Research and Development Program of China (2016YFD0500506), the National High Technology Research and Development Program of China (2013AA10230602), the '111' Project (B16044), China Agriculture Research System (CARS-35), Jinxinnong University Animal Science Developmental Foundation and Hunan Co-Innovation Center of Animal Production Safety, CICAPS.

The authors' contributions are as follows: X. W., G. W., D. L. and J. W. designed the research; X. W., C. F. and G. L. conducted the animal management and sample collection; X. W. conducted the biological experiments and analysed the data; Y. Z. extracted the protein from intestinal mucosa; X. W., G. W. and $\mathrm{J}$. W. wrote the manuscript; and J. W. had primary responsibility for the final content. All authors read and approved the final manuscript.

The authors declare that there are no conflicts of interest. 


\section{Supplementary material}

For supplementary material/s referred to in this article, please visit https://doi.org/10.1017/S0007114518000375

\section{References}

1. Wu G, Bazer FW, Wallace JM, et al. (2006) Board-invited review: intrauterine growth retardation: implications for the animal sciences. J Anim Sci 84, 2316-2337.

2. Lockwood CJ \& Weiner S (1986) Assessment of fetal growth. Clin Perinatol 13, 3-35.

3. Arias F (1977) The diagnosis and management of intrauterine growth retardation. Obstet Gynecol 49, 293-298.

4. McMillen IC \& Robinson JS (2005) Developmental origins of the metabolic syndrome: prediction, plasticity, and programming. Physiol Rev 85, 571-633.

5. Wells JC (2012) Body composition in infants: evidence for developmental programming and techniques for measurement. Rev Endocr Metab Disord 13, 93-101.

6. Wang J, Chen L, Li D, et al. (2008) Intrauterine growth restriction affects the proteomes of the small intestine, liver, and skeletal muscle in newborn pigs. $J$ Nutr 138, 60-66.

7. Wang X, Lin G, Liu C, et al. (2014) Temporal proteomic analysis reveals defects in small-intestinal development of porcine fetuses with intrauterine growth restriction. $J$ Nutr Biochem 25, 785-795.

8. Wang X, Wu W, Lin G, et al. (2010) Temporal proteomic analysis reveals continuous impairment of intestinal development in neonatal piglets with intrauterine growth restriction. J Proteome Res $\mathbf{9}, 924-935$.

9. Purup S, Vestergaard M, Pedersen LO, et al. (2007) Biological activity of bovine milk on proliferation of human intestinal cells. J Dairy Res 74, 58-65.

10. Stelwagen K, Carpenter E, Haigh B, et al. (2009) Immune components of bovine colostrum and milk. J Anim Sci 87, 3-9.

11. Danielsen M, Pedersen LJ \& Bendixen E (2011) An in vivo characterization of colostrum protein uptake in porcine gut during early lactation. J Proteomics 74, 101-109.

12. Tuo W, Zhu D \& Bazer FW (1996) Transfer of heterologous immunoglobulin into the uterine lumen of pigs. I Reprod Immunol 32, 145-155.

13. Sangild PT (2003) Uptake of colostral immunoglobulins by the compromised newborn farm animal. Acta Vet Scand Suppl 98, $105-122$.

14. Wu G (1998) Intestinal mucosal amino acid catabolism. J Nutr 128, 1249-1252.

15. Wang X, Ou D, Yin J, et al. (2009) Proteomic analysis reveals altered expression of proteins related to glutathione metabolism and apoptosis in the small intestine of zinc oxide-supplemented piglets. Amino Acids 37, 209-218.

16. Wang X, Yang F, Liu C, et al. (2012) Dietary supplementation with the probiotic Lactobacillus fermentum 15007 and the antibiotic aureomycin differentially affects the small intestinal proteomes of weanling piglets. J Nutr 142, 7-13.

17. Liu C, Lin G, Wang X, et al. (2013) Intrauterine growth restriction alters the hepatic proteome in fetal pigs. $J$ Nutr Biochem 24, 954-959.

18. Wang T, Liu C, Feng C, et al. (2013) IUGR alters muscle fiber development and proteome in fetal pigs. Front Biosci (Landmark Ed) 18, 598-607.

19. Lin G, Liu C, Feng C, et al. (2012) Metabolomic analysis reveals differences in umbilical vein plasma metabolites between normal and growth-restricted fetal pigs during late gestation. J Nutr 142, 990-998.

20. Wu WZ, Wang XQ, Wu GY, et al. (2010) Differential composition of proteomes in sow colostrum and milk from anterior and posterior mammary glands. J Anim Sci $\mathbf{8 8}$, 2657-2664.

21. Wang X, Qiao S, Yin Y, et al. (2007) A deficiency or excess of dietary threonine reduces protein synthesis in jejunum and skeletal muscle of young pigs. J Nutr 137, 1442-1446.

22. Tom B \& Tirra S (1998) 2-D Electrophoresis: Using Immobilized pH Gradients, Principles \& Methods. Uppsala: Amersham Pharmacia Biotech.

23. Wang J, Ying T, Wang H, et al. (2005) 2-D reference map of Bacillus anthracis vaccine strain A16R proteins. Proteomics 5 , 4488-4495.

24. Lilley KS (2003) Protein profiling using two-dimensional difference gel electrophoresis (2-D DIGE). Curr Protoc Protein Sci Chapter 22, Unit 22.2.

25. Hosokawa M (2008) Structure and catalytic properties of carboxylesterase isozymes involved in metabolic activation of prodrugs. Molecules 13, 412-431.

26. Wang J, Wu Z, Li D, et al. (2012) Nutrition, epigenetics, and metabolic syndrome. Antioxid Redox Signal 17, 282-301.

27. He Q, Ren P, Kong X, et al. (2011) Intrauterine growth restriction alters the metabonome of the serum and jejunum in piglets. Mol Biosyst 7, 2147-2155.

28. Wang T, Huo YJ, Shi F, et al. (2005) Effects of intrauterine growth retardation on development of the gastrointestinal tract in neonatal pigs. Biol Neonate 88, 66-72.

29. Sangild PT, Thymann T, Schmidt M, et al. (2013) Invited review: the preterm pig as a model in pediatric gastroenterology. J Anim Sci 91, 4713-4729.

30. Devillers N, van Milgen J, Prunier A, et al. (2004) Estimation of colostrum intake in the neonatal pig. Anim Sci $\mathbf{7 8}$, 305-313.

31. Li P, Kim SW, Li X, et al. (2008) Dietary supplementation with cholesterol and docosahexaenoic acid increases the activity of the arginine-nitric oxide pathway in tissues of young pigs. Nitric Oxide 19, 259-265.

32. Mezdour H, Larigauderie G, Castro G, et al. (2006) Characterization of a new mouse model for human apolipoprotein A-I/C-III/A-IV deficiency. J Lipid Res 47, 912-920.

33. Kalogeris TJ, Holden VR \& Tso P (1999) Stimulation of jejunal synthesis of apolipoprotein A-IV by ileal lipid infusion is blocked by vagotomy. Am J Physiol 277, G1081-G1087.

34. Kalogeris TJ, Monroe F, Demichele SJ, et al. (1996) Intestinal synthesis and lymphatic secretion of apolipoprotein A-IV vary with chain length of intestinally infused fatty acids in rats. J Nutr 126, 2720-2729.

35. Kalogeris TJ \& Painter RG (2001) Adaptation of intestinal production of apolipoprotein A-IV during chronic feeding of lipid. Am J Physiol Regul Integr Comp Physiol 280, R1155-R1161.

36. Guilmeau S, Buyse M, Tsocas A, et al. (2003) Duodenal leptin stimulates cholecystokinin secretion: evidence of a positive leptin-cholecystokinin feedback loop. Diabetes $\mathbf{5 2}$, 1664-1672.

37. Rodriguez MD, Kalogeris TJ, Wang XL, et al. (1997) Rapid synthesis and secretion of intestinal apolipoprotein A-IV after gastric fat loading in rats. Am $J$ Physiol 272, R1170-R1177.

38. Kalogeris TJ, Tsuchiya T, Fukagawa K, et al. (1996) Apolipoprotein A-IV synthesis in proximal jejunum is stimulated by ileal lipid infusion. Am J Physiol 270, G277-G286.

39. Wang W, Degroote J, Van Ginneken C, et al. (2016) Intrauterine growth restriction in neonatal piglets affects small 
intestinal mucosal permeability and mRNA expression of redox-sensitive genes. FASEB J 30, 863-873.

40. Henderson A \& Hershey JW (2011) The role of eIF5A in protein synthesis. Cell Cycle 10, 3617-3618.

41. Henderson A \& Hershey JW (2011) Eukaryotic translation initiation factor (eIF) 5A stimulates protein synthesis in Saccharomyces cerevisiae. Proc Natl Acad Sci U S A 108, 6415-6419.

42. Gandin V, Miluzio A, Barbieri AM, et al. (2008) Eukaryotic initiation factor 6 is rate-limiting in translation, growth and transformation. Nature 455, 684-688.

43. Kaul G, Pattan G \& Rafeequi T (2011) Eukaryotic elongation factor-2 (eEF2): its regulation and peptide chain elongation. Cell Biochem Funct 29, 227-234.

44. Rhee SG, Chae HZ \& Kim K (2005) Peroxiredoxins: a historical overview and speculative preview of novel mechanisms and emerging concepts in cell signaling. Free Radic Biol Med 38, $1543-1552$.

45. Galligan JJ, Fritz KS, Backos DS, et al. (2014) Oxidative stressmediated aldehyde adduction of GRP78 in a mouse model of alcoholic liver disease: functional independence of ATPase activity and chaperone function. Free Radic Biol Med 73, $411-420$

46. Salces-Ortiz J, Ramon M, Gonzalez C, et al. (2015) Differences in the ovine HSP90AA1 gene expression rates caused by two linked polymorphisms at its promoter affect rams sperm DNA fragmentation under environmental heat stress conditions. PLOS ONE 10, e0116360.

47. Le Masson F \& Christians E (2011) HSFs and regulation of Hsp70.1 (Hspa1b) in oocytes and preimplantation embryos: new insights brought by transgenic and knockout mouse models. Cell Stress Chaperones 16, 275-285.

48. Berchtold MW \& Villalobo A (2014) The many faces of calmodulin in cell proliferation, programmed cell death, autophagy, and cancer. Biochim Biophys Acta 1843, 398-435.
49. Sasaki Y \& Hidaka H (1982) Calmodulin and cell proliferation. Biochem Biophys Res Commun 104, 451-456.

50. Rasmussen CD \& Means AR (1987) Calmodulin is involved in regulation of cell proliferation. EMBO J 6, 3961-3968.

51. Colomer JM, Terasawa M \& Means AR (2004) Targeted expression of calmodulin increases ventricular cardiomyocyte proliferation and deoxyribonucleic acid synthesis during mouse development. Endocrinology 145, 1356-1366.

52. Jeon YJ, Kim DH, Jung H, et al. (2010) Annexin A4 interacts with the NF-kappaB p50 subunit and modulates NF-kappaB transcriptional activity in a $\mathrm{Ca} 2+-$ dependent manner. Cell $\mathrm{Mol}$ Life Sci 67, 2271-2281.

53. Boersma HH, Kietselaer BL, Stolk LM, et al. (2005) Past, present, and future of annexin A5: from protein discovery to clinical applications. J Nucl Med 46, 2035-2050

54. Masuda J, Takayama E, Satoh A, et al. (2004) Levels of annexin $\mathrm{IV}$ and $\mathrm{V}$ in the plasma of pregnant and postpartum women. Thromb Haemost 91, 1129-1136.

55. Corsten MF, Hofstra L, Narula J, et al. (2006) Counting heads in the war against cancer: defining the role of annexin A5 imaging in cancer treatment and surveillance. Cancer Res $\mathbf{6 6}$, $1255-1260$

56. Bu HF, Zuo XL, Wang X, et al. (2007) Milk fat globule-EGF factor 8/lactadherin plays a crucial role in maintenance and repair of murine intestinal epithelium. J Clin Invest 117, 3673-3683.

57. Ait-Oufella H, Kinugawa K, Zoll J, et al. (2007) Lactadherin deficiency leads to apoptotic cell accumulation and accelerated atherosclerosis in mice. Circulation 115, 2168-2177.

58. Coppolino MG \& Dedhar S (1998) Calreticulin. Int J Biochem Cell Biol 30, 553-558.

59. Obeid M, Tesniere A, Ghiringhelli F, et al. (2007) Calreticulin exposure dictates the immunogenicity of cancer cell death. Nat Med 13, 54-61. 